\title{
La excedencia especial por matrimonio en las Corporaciones locales
}

\author{
por \\ JOSE CEVA SEBASTIA \\ Abogado
}

SUMARI0: 1. Introducción. 2. Irretroactividad del Decreto de 1 de marzo de 1962. 3. Nuevas situaciones creadas por el Decreto de 1 de marzo de 1962.

\section{INTRODUCCION}

Los principios de igualdad ante la ley, de la mujer y el varón, que actualmente se predica y reconoce por doquier y que en la concienda pública ha adquirido valor de postulado, han sido fruto de una lenta evolución. Las doctrinas igualatorias nacen con el Cristianismo y se influjo se percibe ya ampliamente en la última fase del Derecho romano. Durante la Edad Media se desarrollan con todo vigor en la esfera del Derecho privado, mientras que en el Derecho público sigue imperando con gran amplitud el principio de la incapacidad de la mujer.

Durante el siglo pasado se inicia el reconocimiento de la aptitud de la mujer para participar en quehacer público y en el presente siglo asistimos al fenómeno de la irrupción de la mujer en las esferas de la actividad pública.

Nuestra Patria no se ha sustraído de este fenómeno universal. En dos leyes principales culmina la evolución de nuestro ordenamiento jurídico en este sentido; una afecta al campo del Derecho privado, fué la Ley de 24 de abril de 1958, que suprimió las escasas incapacidades que por razón del sexo subsistían en nuestro Código civil. En el campo del Derecho público ha 
cumplido idéntica misión la Ley de 22 de julio de 1961, cuyo artículo 1.- dice: «La Ley reconoce a la mujer los mismos derechos que al varón para el ejercicio de toda clase de actividades políticas, profesionales y de trabajo, sin más limitaciones que las establecidas en la presente Ley».

La citada Ley supone la consagración definitiva de la igualdad de derechos del hombre y la mujer. En ella se declaran derogadas las disposiciones que se opongan a la misma; entre las disposiciones afectadas se encontraba el artículo 61 del Reglamento de Funcionarios de Administración local de 30 de mayo de 1952 por su incompatibilidad con el espíritu de la Ley.

El Gobierno, haciendo uso de la facultad que le concedía la tercera disposición final «para mejor cumplimiento de los preceptos que se contienen en la Ley y, asimismo, para la adaptación a sus preceptos de las situaciones creadas hasta el momento de su vigencia, respetando los derechos adquiridos», publicó el Decreto número 399 de 1 de marzo de 1962, que responde a aquella finalidad.

Este Decreto, como toda norma jurídica, requiere, como labor preparatoria a su aplicación, un doble estudio del mismo.

1. Fijar el ámbito de aplicación con relación al tiempo y al espacio y a las personas. En cuanto a los dos últimos aspectos, prescindiremos de ellos por no ofrecer especialidad alguna; con relación al espacio se aplica en todo el territorio nacional, incluídas las Provincias ecuatoriales. Con relación a las personas se aplica exclusivamente a los funcionarios de las Corporaciones locales que contraigan matrimonio. Unicamente con relación al tiempo se suscitan problemas de derecho transitorio de los que después nos ocuparemos.

2.- El esclarecimiento del sentido del mismo e integración de las lagunas que en él pueden observarse.

Siguiendo este plan, estudiaremos en primer lugar las relaciones entre el derogado artículo 61 del Reglamento de 30 de mayo de 1952 y el Decreto número 399, y a continuación examinaremos las dudas y problemas que esta disposición suscita. 


\section{IRRETROACTTVIDAD DEL DECRETO DE 1 DE MARZO DE 1962}

El primer problema que su aplicación presenta es de cierecho transitorio. ¿Tiene carácter retroactivo el Decreto de 1 de marzo de 1962, o bien no hay que reconocerle este carácter? De la solución que se le dé se derivan muy importantes consecuencias de muy diverso orden, que como veremos se refieren a la subsistencia de ciertas situaciones jurídicas.

El Decreto número 399 en su disposición derogatoria se limita a decir: "De acuerdo con lo prevenido en la Ley número 56/61 de junio pasado, se consideran derogados a partir de 1 de enero de 1962, el apartado $c$ ) del artículo $56 \mathrm{y}$ el artículo 61, ambos del Reglamento de Funcionarios de Administración local, de 30 de mayo de 1952». En ella no se resuelve el problema, pues ni remotamente alude a él. ¿Qué criterio debe seg uirse? FrrRara, al tratar de la retroactividad de las normas, dice que todo hecho jurídico, sea acaecimiento causal o acto jurídico, está regulado, tanto por lo que afecta a sus condiciones de forma o de fondo, cuanto por lo que se refiere a sus efectos pasados, presentes y futuros, por la ley del ciempo en que el hecho fué jurídicamente cumplido, salvo que la nueva ley excluya en mayor o menor grado la eficacia del ordenamiento jurídico antiguo.

Así, pues, la entrada en vigor de una nueva norma jurídica no altera las situaciones nacidas y consumadas bajo el imperio de la norma derogada; más aún, la antigua norma regula también. los hechos pendientes que no han producido efecto por no haber desenvuelto la totalidad de la relación jurídica regulada por la antigua disposición, e incluso los futuros que puedan producirse, excepto que la nueva norma excluya más o menos ampliamente los efectos de la derogada.

En nuestro ordenamiento jurídico, el carácter no retroactivo de las normas viene expresado con carácter general en el artículo 3. del Código civil, que es de aplicación general. Como el Decreto núm. 399 no contiene declaración alguna sobre esta cuestión, es perfectamente aplicable aquella disposición general. Asimismo la disposición adicional dice: «lo dispuesto en el presente 
Decreło no alcanza a las situaciones administrativas de los funcionarios femeninos de Administración local, surgidas o creadas con anterioridad al día 1 del corriente año», o sea, que las situaciones anteriores al 1 de enero de 1962 quedan inalterables; luego el Decreto núm. 399 no tiene efectos retroactivos. La única excepción a esta regla general la recoge en la đisposición transitoria, en relación con el artículo 1.o, número uno, en la que determina los efectos retroactivos del Decreto para los funcionarios femeninos que hubieran contraído matrimonio con posterioridad al 1 de enero de 1962.

El no tener el citado Decreto efectos retroactivos significa que las situaciones creadas al amparo del artículo 61 del Reglamento de Funcionarios de Administración local, subsisten en toda su amplitud y siguen reguladas por el artículo 61 y concordantes.

La derogación del artículo 61 no significa que las situaciones jurídicas nacidas cuando la citada disposición se hallaba vigente, queden extinguidas automáticamente; lo contrario sería antijurídico. Una vez que los hechos quedaron consumados bajo el imperio del artículo 61, creando una situación jurídica nueva, ésta no puede ser alterada por la simple derogación del mismo, sino que requiere una declaración expresa o tácita en contrario, declaración que el Decreto 399 no contiene. La derogación de una norma no implica necesariamente la modificación de los casos que la misma reguló. El artículo 61 no puede aplicarse a hechos nuevos, pues ha sido derogado, pero sí a las situaciones nacidas durante su vigencia.

La primera consecuencia que se deriva de lo antedicho es que el funcionario femenino, excedente por matrimonio conforme a lo dispuesto por el artículo 61 del repetido Reglamento, no puede solicitar el reingreso al amparo del Decreto núm. 399, pues para que así fuese se requeriria que éste tuviese efectos retroactivos, y ya hemos demostrado que no los tiene. Los funcionarios que se hai?en en acuella situación, únicemente podrán pedir e: ruevo ingreso en los casos de disolución dei vínculo o bien cesación o suspensión de la vida conyugal.

Otra consecuemcia es la subsistencia de la situación de exce. äencia especial por razón de matrimonio. Se trata de una situa- 
ción distinta de aquellas que, conforme al Decreto 399, puede optar la mujer funcionario que contraiga matrimonio con posterioridad al 31 de diciembre de 1961. Basta una simple lectura comparativa entre el supuesto del artículo 61 del Reglamento y los casos del Decreto 399 para comprender que son supuestos distintos; fácilmente se deduce la voluntad del legislador de crear nuevas situaciones jurídicas aplicables a los funcionarios femeninos que contraigan matrimonio, pero dejando subsistentes las que hasta entonces existían. No cabe la interpretación extensiva para comprender en el Decreto 399 casos no queridos por el legislador, como se deduce claramente del artículo 1., y sobre todo del párrafo primero del citado Decreto.

Hemos dicho anteriormente que el funcionario femenino en situación de excedencia especial por razón de matrimonio, no puede imponer a la Corporación su readmisión basándose en el Decreto núm. 399, y a sensu contrario tampoco la Administración podrá obligar al reingreso al funcionario excedente; ahora bien, ¿podría ser nuevamente admitida en virtud de un acuerdo libre entre la Corporación y el funcionario femenino? Aparentemente un criterio afirmativo parece imponerse, pues si las mujeres casadas pueden ser funcionarios actualmente, parece que no debe existir obstáculos para que, puestos de acuerdo ambos interesados, proceder a la readmisión del funcionario femenino. Pero en buena lógica la realidad es otra. Este problema está ligado a lo aducido anteriormente al exponer el carácter no reretroactivo del Decreto 399. Al carecer éste de valor retroactivo, subsisten, como anteriormente decíamos, las situaciones surgidas al amparo del artículo 61 del Reglamento y, por consiguiente, la situación de excedencia especial por matrimonio no puede terminar por voluntad de los interesados, sino cuando cese la causa que los originó, bien por viudedad, bien por incapacidad del marido o separación, según lo resuelto por la Dirección General de Administración Local en Resolución de 9 de diciembre de 1953.

¿Podría concursar u opositar de nuevo el funcionario excedente por matrimonio para obtener de nuevo la plaza, con posterioridad al Decreto 399 ? Indudablemente no, pues ya es funcionario y su suficiencia quedó demostrada en un anterior concur- 
so $u$ oposición; únicamente ha cesado de estar en servicio activo y si nuevamente ingresare, se daría el absurdo de que una misma persona figurase dos veces relacionada en el mismo escalafón en situaciones contrapuestas, o sea excedente y en activo al propio tiempo. En cambio no existe obstáculo para opositar o concursar a una plaza de distinta naturaleza, siempre que no fuese requisito indispensable para participar en ellos, el estar en posesión previa de la plaza en la cual se encuentra excedente.

Admitida la subsistencia de la situación de excedencia especial por matrimonio del artículo 61, hay que determinar el régimen jurídico de los funcionarios femeninos que se hallan en esta situación. El Reglamento nada dispone al respecto, se limita a declarar cuando procede la situación de excedencia especial, silenciando cuestiones tan importantes como los casos en que cesará esta situación y cómo se efectuará el reingreso.

Para llenar las lagunas del Reglamento habrá que acudir a las fuerzas expansivas del Derecho positivo, o sea a los principios extraídos de las instituciones afines del Reglamento. Este regula con más detalle la excedencia activa, forzosa y voluntaria; a ellos habrá que acudir para suplir las deficiencias que se observan en la excedencia especial por matrimonio.

El momento en que cesará esta situación será cuando cese la causa que la provoca. Según la Resolución de la Dirección General de Administración Local de fecha 9 de diciembre de 1953 , cesa en los casos de incapacidad del marido, viudedad o separación legal. Es una amplia interpretación. Siguiendo este criterio nosotros estimamos que la enumeración anterior debe ser ampliada hasta incluirse en la misma todo lo que se refiera a causas de disolución del matrimonio, en que además de la viudedad, incapacidad y separación, deberá comprenderse también la declaración de fallecimiento, dispensa del matrimonio rato, nulidad del matrimonio, incluso en este último caso aunque en la sentencia se declarase la mala fe de la mujer, pues los efectos civiles de la resolución judicial son independientes de los efectos administrativos.

No creemos necesario hacer hincapié que en todos los supuestcs anteriores, salvo el del fallecimiento del marido, como se re- 
fieren a modificaciones del estado civil de las personas, se requerirá la correspondiente resolución de los órganos judiciales competentes, para que sus efectos puedan ser apreciados por la Corporación.

Otro problema que se presenta es si una vez disuelto el matrimonio, el funcionario femenino adquirirá automáticamente la cualidad de funcionario en activo o se requerirá una petición de su parte. Indudablemente esta última solución es la que debe prevalecer y la sostenemos basándonos en las disposiciones del Reglamento de Funcionarios de Administración local, que regula las otras modalidades de excedencia, pues esa petición se exige para el reingreso en la excedencia activa (art. 60, n.o 2), por regla general en la forzosa (art. 62,c), art. 58, núms. 3 y 4), y en la excedencia voluntaria (art. 63,1). Si no se solicita el reingreso habrá que considerar que pasa a la situación de excedente voluntario, pues el Reglamento lo dispone así para la excedencia forzosa (art. 58, 4), y para la excedencia activa (art. 60, 2, inciso 2,9 ), y para ambas conjuntamente (art. 62, c).

$\mathrm{Si}$ el funcionario femenino solicita el reingreso y no existe: plaza vacante, pasará a la situación de expectación de destino, y será preferido, en igualdad de condiciones, a uno que se halle en situación de excedencia voluntaria, pues la situación de éste ha sido querida espontáneamente por el mismo o impuesta por su negligencia (caso del art. 62 b) y c) del Reglamento) u otras. causas relacionadas con el servicio (caso del art. $62 d$ ), mientras que en el otro supuesto ha sido determinada sin la voluntad del funcionario, y puede que hasta en contra de su voluntad, aun cuando el hecho origen sea siempre voluntario, de ahí la razón de justicia y de lógica de esta preferencia.

\section{NUEVAS SITUACIONES CREADAS POR EL DECRETO DE 1 DE MARZO DE 1962}

El Decreto de 1 de marzo de 1962, núm. 399, regula la situación de los funcionarios femeninos que contraigan matrimonio con posterioridad a 31 de diciembre de 1961, y deroga las disposiciones del Reglamento de Funcionarios de Administración local 
de 30 de mayo de 1952, incompatible con la Ley de 22 de julio de 1961.

El citado Decreto ha creado nuevas situaciones en las que quedará el funcionario femenino cuando contraiga matrimonio. En realidad las situaciones creadas por este Decreto son innecesarias; equiparados en derechos y deberes el hombre y la mujer, según disposición de la reciente Ley, no había razón alguna para crear un régimen jurídico nuevo para la mujer que contrajese matrimonio; bastaba con conservar la excedencia por matrimonio del artículo 61 del Reglamento con algunos retoques, como sería el atribuirle carácter facultativo para el funcionario que contrajera matrimonio, señalándole un plazo prudencial para que usase de su derecho de elección, especificando que si no hacía uso quedaba sometida al régimen general de los demás funcionarios. Las demás situaciones pueden regirse por las reglas generales del Reglamento, sin que padezcan los derechos de la mujer. Así la renuncia, en la que no hay más diferencia, sino lo relativo a la indemnización, y la excedencia, si suprimimos el arbitrario plazo de cinco años. Tampoco existe razón alguna, dado el espíritu amplio que guía a la Ley de 22 de julio de 1961, para facultar a la Corporación a declarar al funcionario femenino en alguna de las situaciones que el Decreto prevé, en defecto de la elección de éste. Facultad discrecional concedida a las Corporaciones que no se basa en ninguna razón de conveniencia o utilidad de la causa pública, más bien parece una supervivencia encubierta de viejas ideas y que desde luego contradice el espíritu de la Ley sobre derechos profesionales y políticos de la mujer.

Siendo la finalidad del Decreto núm. 399 la derogación del artículo 61 y apartado $c$ ) del artículo 56 del Reglamento de Funcionarios de Administración local, ya virtualmente derogados por la Ley de 22 de julio de 1961, era suficiente para la protección a la familia, si esta es la razón del especial régimen jurídico que establece el Decreto para la mujer casada, con otorgar al funcionario femenino la facultad de pedir la excedencia voluntaria cuando contraiga matrimonio, aunque no contase con un año de servicios a la Corporación.

Por otra parte hubiese sido laudable que el Decreto, haciendo 
uso de la autorización de la tercera disposición final de la Ley de 22 de julio de 1961, para adaptar al espíritu de ésta las situaciones creadas hasta el momento de su vigencia, dictase reglas que permitiesen a los funcionarios femeninos, en situación de licencia especial por matrimonio, continuar en ella o bien el obtener el reingreso si así lo deseaba, no por razones de justicia, puesto que el Decreto, desde este punto de vista es correcto, sino por razón de equidad, ya que fueron apartados del servicio contra su voluntad tal vez en la mayoría de los casos.

El primer problema que nos presenta el Decreto 399, es el determinar la naturaleza de la situación de excedencia que regula en el apartado c) del artículo 1.o. Al darle la denominación de excedencia voluntaria, parece equipararla a la del apartado $d$ ) del artículo 56 del Reglamento de Funcionarios. Sin embargo, existen notables diferencias entre ambas situaciones, así como ciertas afinidades.

Tienen de común: a) ambas son completamente voluntarias; b) necesitan, para ser concedidas, la solicitud del interesado, y c) las dos situaciones dan lugar al cese del servicio activo.

Junto a estas notas comunes, existen diferencias que demuestran que se trata de instituciones distintas, aunque afines: $a$ ) Por razón de los sujetos, que la excedencia voluntaria regulada por el Reglamento, se predica de todos los funcionarios, cualquiera que sea su sexo, mientras que la del Decreto 399 , sólo de los funcionarios femeninos que contraigan matrimonio después de su ingreso; b) Por razón de la causa, en la primera es la voluntad del funcionario que puede obedecer a muy diversos motivos de índole personal, mientras que en la segunda existe una razón próxima, que es la voluntad del funcionario femenino, pero la verdadera causa es remota, y es únicamente el matrimonio; $c$ ) De tiempo. En la regulada por el artículo 62, encontramos dos límites; uno inicial, «que cuenten, al menos, un año de servicios a la Corporación»; otra limitación de término, «no podrá exceder de diez años». Mientras que en la excedencia regulada por el Decreto 399 no existe limitación inicial alguna, aunque el funcionario femenino llevase menos de un año de servicio a la Corporación, podía optar por la excedencia, y en cuanto al límite final, éste queda reducido a sólo cinco años como máximo, y d) De or- 
den formal; en la excedencia voluntaria normal, se exige como requisito para concederse, que el funcionario no se halle sometido a expediente disciplinario, requisito que no se exige en la excedencia por matrimonio, del Decreto 399. En el supuesto de hallarse el funcionario femenino que pide la excedencia por matrimonio, sujeto a expediente disciplinario, la duda que surge es si éste quedará paralizado; indudablemente estimamos que no. La dinámica del expediente continuará por los cauces normales, adaptándose en lo posible su tramitación y solución a la especial situación del funcionario; no hay motivo para suponer la existencia de una crisis subjetiva del expediente que produjese su paralización o un desarrollo anormal del mismo. Su resultado, tanto favorable como desfavorable, afectaría al funcionario.

En resumen podemos decir que una y otra modalidad de excedencia se hallan en relación de género a especie; el género lo constituye la excedencia del artículo 62 del Reglamento, y la especie la excedencia voluntaria por razón de matrimonio del Decreto 399. Consecuencia de esto en la posibilidad de aplicar como supletorias, en cuanto lo permita las peculiaridades del mismo, a la excedencia del Decreto 399 , las disposiciones generales que sobre excedencia voluntaria contiene el Reglamento.

Pasemos a exponer otro problema que suscita la redacción del Decreto 399. El plazo de excedencia voluntaria según el artículo primero $c$ ), será por tiempo no inferior a un año ni superior a cinco. El funcionario femenino, al finalizar este plazo podrá optar por el reingreso, pero supongamos que no lo haga, ¿en qué situación quedará este funcionario? Ante el silencio del Decreto 399 habrá que aplicar las reglas generales, así, pues, se entenderá que renuncia al cargo.

Si opta por el reingreso, puede ocurrir que existan plazas vacantes, en cuyo caso no hay problema, pero si no las hubiese en este caso, ¿en qué situación quedará la solicitante? Podría considerarse que pasa a la situación de excedencia forzosa, pero este criterio no es sostenible por las siguientes razones: que se trata de una situación totalmente voluntaria la excedencia por razón de matrimonio, tal como la regula el Decreto 399; que participa de la misma naturaleza de la excedencia voluntaria, con la que se halla en relación de género a especie, según hemos señalado REVL-1963, núm. 128. CEVA SEBASTIA, JOSE. LA EXCEDENCIA ESPECIAL POR MATRIMONIO ... 
antes, por consiguiente son aplicables como supletorias las reglas generales sobre excedencia voluntaria del Reglamento de 30 de mayo de 1952; por ello estimamos que el funcionario femenino pasaría a la situación de expectación de destino una vez que opta por el reingreso.

Al transcurrir el término de los cinco años, duración máxima de la excedencia voluntaria que regula el Decreto 399 , el funcionario femenino que estuviese en dicha situación no podrá solicitar una nueva excedencia teniendo como causa el matrimonio, pero sí, como es lógico, la excedencia voluntaria normal, si reúne los requisitos para ello y no se interpreta el año de servicios que exige el artículo 62, 1.a) del Reglamento, como prestado inmediatamente antes de la nueva concesión de excedencia.

El Decreto 399 concede la facultad de elegir en primer lugar al funcionario femenino; si éste no hiciese uso de esta facultad dentro de un mes desde la celebración del matrimonio, puede la Corporación local declarar al funcionario femenino en cualquiera de las tres situaciones que se regulan en el artículo 1.0 del citado Decreto. Como no se establece ningún plazo para que haga uso de esa facultad la Corporación, puede interpretarse que la posee indefinidamente; pero esa indeterminación puede dar origen a situaciones extraordinariamente confusas. Supongamos que se suprime una plaza que no tiene el carácter de única en la Corporación. Conforme al artículo 58 del Reglamento debe declararse en situación de excedencia forzosa al funcionario más moderno, pero imaginemos que el funcionario afectado sea varón o femenino no casado y que exista una mujer casada, funcionario más antiguo, que no haya usado de la opción que le concede el Decreto y que, a su vez, la Corporación tampoco haya declarado a la interesada en alguna de las situaciones del Decreto 399. Indudablemente podrá la Corporación declarar en ese momento al funcionario femenino casado en alguna de las situaciones previstas por el repetido Decreto, pues su facultad, como hemos dicho, no está sometida a límite alguno por razón de tiempo; pero el problema que planteamos es este: ¿tendrá la Corporación la facultad de declarar al funcionario femenino, que se halle en la situación antes expresada, excedente forzoso con preferencia a otro funcionario que no se halle en el indicado caso, pero siendo 
más moderno en el servicio? La tesis afirmativa podría sostenerse basándose en el principio «si la ley autoriza lo más, implícitamente autoriza lo menos», si la Corporación tiene facultad para declarar al funcionario femenino en situación de renunciante al cargo, con mayor razón declararlo en situación de excedencia forzosa.

No obstante parece más viable el punto de vista negativo, que puede sostenerse con los argumentos siguientes: a) Que el Decreto 399 limita las facultades de la Corporación a la elección entre uno de los casos que la misma regula. b) Así como a los ciudadanos les está permitido todo aquello que no esté expresamente prohibido al Estado, y por extensión a las Corporaciones locales, les está prohibido todo aquello que no esté expresamente autorizado por disposición legal; por consiguiente, al reconocerle esta facultad a las Corporaciones, sería atribuirles facultades no concedidas por la Ley; y c) Por último, el obrar de ese modo supondría una infracción del apartado primero del artículo $58 \mathrm{del}$ Reglamento, que establece el orden que en esta clase de excedencias debe seguirse.

También puede darse el caso de que una mujer, ya casada, ingrese como funcionario en la Administración local. A éstas no les será aplicable lo dispuesto en el Decreto 399, pues éste, en su artículo 1. limita su aplicación «a los funcionarios femeninos de la Administración local que contraigan o hubieren contraíđo matrimonio después del 31 de diciembre de 1961». Fácilmente se deduce de su letra que se refiere exclusivamente a aquellas que al ingresar son solteras o viudas; por consiguiente, las que siendo casadas ingresen, se regirán por las reglas generales del Reglamento, pero si durante la prestación del servicio enviudasen y nuevamente contrajesen matrimonio, entonces sí sería de aplicación lo dispuesto en el Decreto 399.

Interesante es también el examinar los efectos que produce la disolución por nulidad del matrimonio contraído por un funcionario femenino. Estos efectos están en íntima relación con la situación administrativa que ésta hubiese optado, o en que hubiese sido declarada por la Corporación. Si la situación en que aquélla quedó fué la continuación en el servicio o en el de exce- 
dencia, serán aplicables las reglas generales, con la única particularidad que no es necesario el transcurso de un año en el excedente, a que alude el Decreto 399, para solicitar el reingreso, por las mismas razones que al tratar la renuncia al cargo expondremos.

La problemática de la renuncia al cargo es más grave, pues hay que determinar los efectos de la nulidad del matrimonio y el fundamento de esos efectos. La renuncia por el funcionario femenino, que ha contraído matrimonio, supone un acto de la Corporación, por el que se acepta la renuncia y con ella se extingue la relación del empleo, se da de baja en el escalafón al funcionario y se ordena el abono de la indemnización; todo ello constituye un acto administrativo. Lo mismo ocurre si es la Corporación, en defecto de elección del funcionario femenino, la que, haciendo uso de las facultades que le concede el Decreto 399, le declara en algunas de las situaciones que el mismo regula. El matrimonio es la causa de estos actos administrativos, y así podemos expresarnos, siguiendo la autorizada opinión de prestigiosos autores, que consideran como causa del acto administrativo el antecedente de hecho que determina y provoca la comisión de aquél. Así, pues, la nulidad del matrimonio produce la nulidad, no la anulabilidad, de este acto administrativo.

Por ello, la consecuencia de la nulidad del matrimonio es la renuncia al cargo y el restablecimiento de la situación de servicio activo, y sus efectos (entre los que se encuentran el reintegro de la indemnización que percibe) se retrotraen al momento en que se produjo el acto administrativo que se declara nulo. Es indiferente que en la ejecutoria de nulidad conste la buena o mala fe de la mujer al contraer matrimonio, pues las mismas no producen efecto administrativo alguno, sino meramente civiles, a tenor de los artículos 69 y siguientes y 1.417 del Código civil, los cuales establecen a su vez las sanciones civiles en que incurre el cónyuge que por su mala fe fuese causa de la nulidad del matrimonio.

Naturalmente que al reintegrarse el funcionario al servicio activo pueden producirse colisiones de derechos de no fácil solución. 